\title{
New investigations at the Middle Stone Age site of Pockenbank Rockshelter, Namibia
}

Isabell Schmidt ${ }^{1, *}$, Götz Ossendorf ${ }^{2}$, Elena Hensel ${ }^{3}$, Olaf Bubenzer ${ }^{3}$, Barbara Eichhorn ${ }^{4}$, Lothar Gessert ${ }^{5}$, Goodman Gwasira ${ }^{6}$, Felix Henselowsky ${ }^{3}$, Emma Imalwa $^{7}$, Martin Kehl $^{3}$, Janet Rethemeyer ${ }^{8}$, Astrid Röpke ${ }^{9}$, Judith Sealy ${ }^{10}$, Ingrid Stenge ${ }^{11} \&$ Madelon Tusenius ${ }^{12}$

\section{Introduction}

In southern Africa, Middle Stone Age sites with long sequences have been the focus of intense international and interdisciplinary research over the past decade (cf. Wadley 2015). Two techno-complexes of the Middle Stone Age — the Still Bay and Howiesons Poort-have been associated with many technological and behavioural innovations of Homo sapiens. The classic model argues that these two techno-complexes are temporally separated 'horizons' with homogenous material culture (Jacobs et al. 2008), reflecting demographic pulses and supporting large subcontinental networks. This model was developed on the basis of evidence from southern African sites regarded as centres of subcontinental developments.

Southern Namibia forms the north-westernmost margin of the geographic distribution of Still Bay and Howiesons Poort techno-complexes (Figure 1). This region therefore

1 Institute of Prehistoric Archaeology, University of Cologne, CRC 806, Bernhard-Feilchenfeld-Straße 11, 50969 Cologne, Germany (Email: isabell.schmidt@uni-koeln.de)

2 School of Geography, Archaeology and Environmental Studies, University of the Witwatersrand, Private Bag 3, Wits, 2050, Johannesburg, South Africa (Email: gotz.ossendorf@wits.ac.za)

3 Institute of Geography, University of Cologne, Albertus-Magnus-Platz, 50923 Cologne, Germany (Email: ehensel@smail.uni-koeln.de; felix.henselowsky@uni-koeln.de; olaf.bubenzer@uni-koeln.de; martin.kehl@uni-koeln.de)

4 Institute of Archaeological Sciences, Goethe University Frankfurt, Norbert-Wollheim-Platz 1, 60629 Frankfurt (Main), Germany (Email: b.eichhorn@em-uni-frankfurt.de)

5 Namib Huib Plateau Park, P.O. Box 5723, Windhoek, Namibia (Email: loges@iway.na)

6 Department of Geography, History and Environmental Studies, University of Namibia, Private Bag 13301, Windhoek, Namibia (Email: ggwasira@unam.na)

7 Archaeology Department, National Museum of Namibia, Windhoek, Namibia (Email: emmaimalwa@gmail.com)

8 Institute for Geology and Mineralogy, University of Cologne, Zülpicher Straße 49a, 50674 Cologne, Germany (Email: janet.rethemeyer@uni-koeln.de)

9 Archaeobotanical Laboratory, Institute of Prehistoric Archaeology, University of Cologne, Weyertal 125, 50931 Cologne, Germany (Email: astrid.roepke@uni-koeln.de)

10 Department of Archaeology, University of Cape Town, Private Bag X3, Rondebosch 7701, South Africa (Email: judith.sealy@uct.ac.za)

11 Department of Geo-Spatial Sciences, Namibia University of Science and Technology, Private Bag 13388, Windhoek, Namibia (Email: ingrid@namibgeovista.com)

12 Natura Viva cc, Cape Town, P.O. Box 12410, Mill Street, Cape Town 8010, South Africa (Email: madelontusenius@gmail.com)

* Author for correspondence (Email: isabell.schmidt@uni-koeln.de)

(C) Antiquity Publications Ltd, 2016

ANTIQUITY 90 353, e2 (2016): 1-6

doi:10.15184/aqy.2016.165 

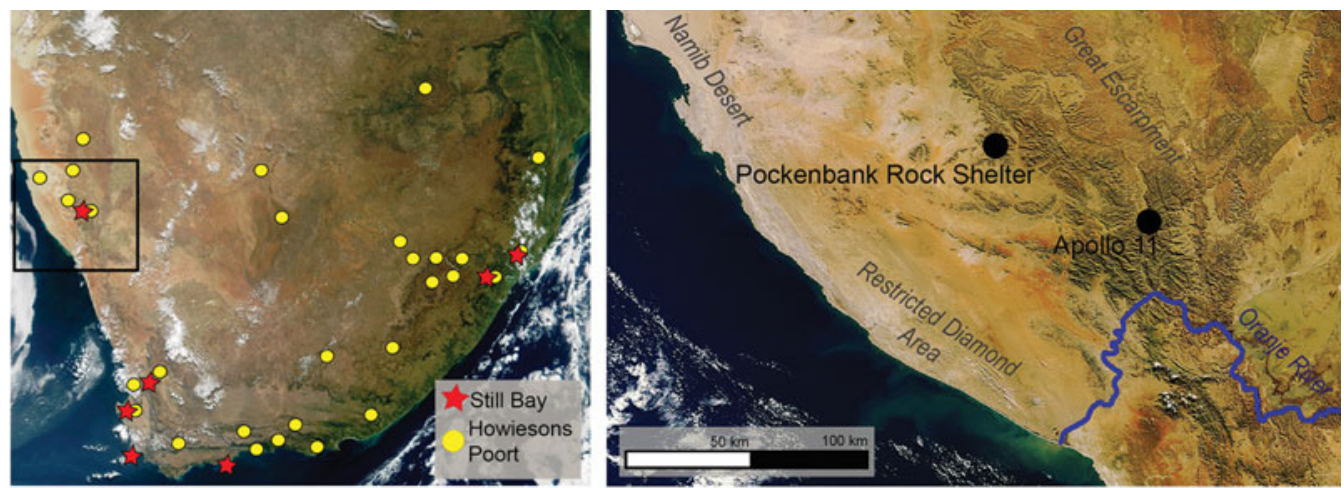

Figure 1. Left: distribution of sites with documented Still Bay and Howiesons Poort techno-complexes. Right: location of Pockenbank Rockshelter and Apollo 11 Rockshelter (source: www.geog.ucsb.edu, www.esa.int).

provides an opportunity to investigate the distribution, persistence and loss of Middle Stone Age technological innovations and adaptive capacities from a peripheral perspective. Approaching this question requires a detailed knowledge of the formation of the archaeological record, its chronological profile, techno-economic characteristics and its relation to changing regional climatic and environmental conditions. This article reports on an interdisciplinary project implemented to generate such data. It applies archaeological and geoarchaeological methods to examine the site at the Pockenbank Rockshelter and its wider geographic setting.

\section{Pockenbank Rockshelter}

The site is located at the interface between the southern Namib Desert and the Great Escarpment (Figure 1). The immediate area is characterised by narrow valleys and gorges of dry river beds, oriented from east to west, episodically draining into shallow basins (vleis) of the Namib.

The spacious shelter opens to the north. The Middle Stone Age deposits were discovered during a test-pit excavation in 1969 (Wendt 1972), and the results subsequently published (Vogelsang 1998). A similarly extensive stratigraphic sequence is known only from the Apollo 11 site, located $80 \mathrm{~km}$ to the south (Vogelsang et al. 2010).

\section{First results}

Between the original work at the Pockenbank Rockshelter and our own work in 2015, unauthorised excavations were conducted leading to considerable damage to in situ material as well as to the 1969 test pit (Figure 2). The 2015 field season therefore started by documenting the extent of the damage, before cleaning the upper part of the former profile and excavating an area of $0.5 \mathrm{~m}^{2}$ (Figure 3). Natural layers were followed, and features, single finds and sampled materials were piece-plotted. The lower part of the sequence down to bedrock was intact, and samples were taken during profile cleaning.

(C) Antiquity Publications Ltd, 2016 

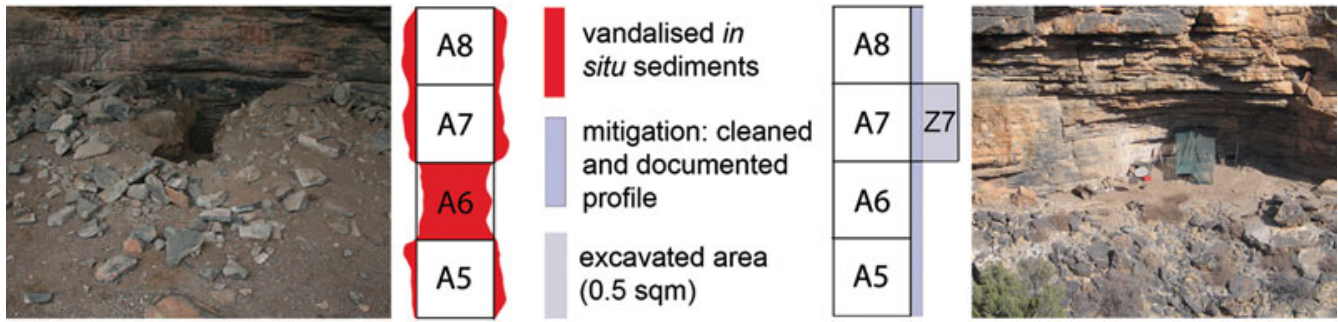

Figure 2. Left: damage of the old 'A'-trench by unauthorised excavations. Right: view of the shelter during excavation in 2015.

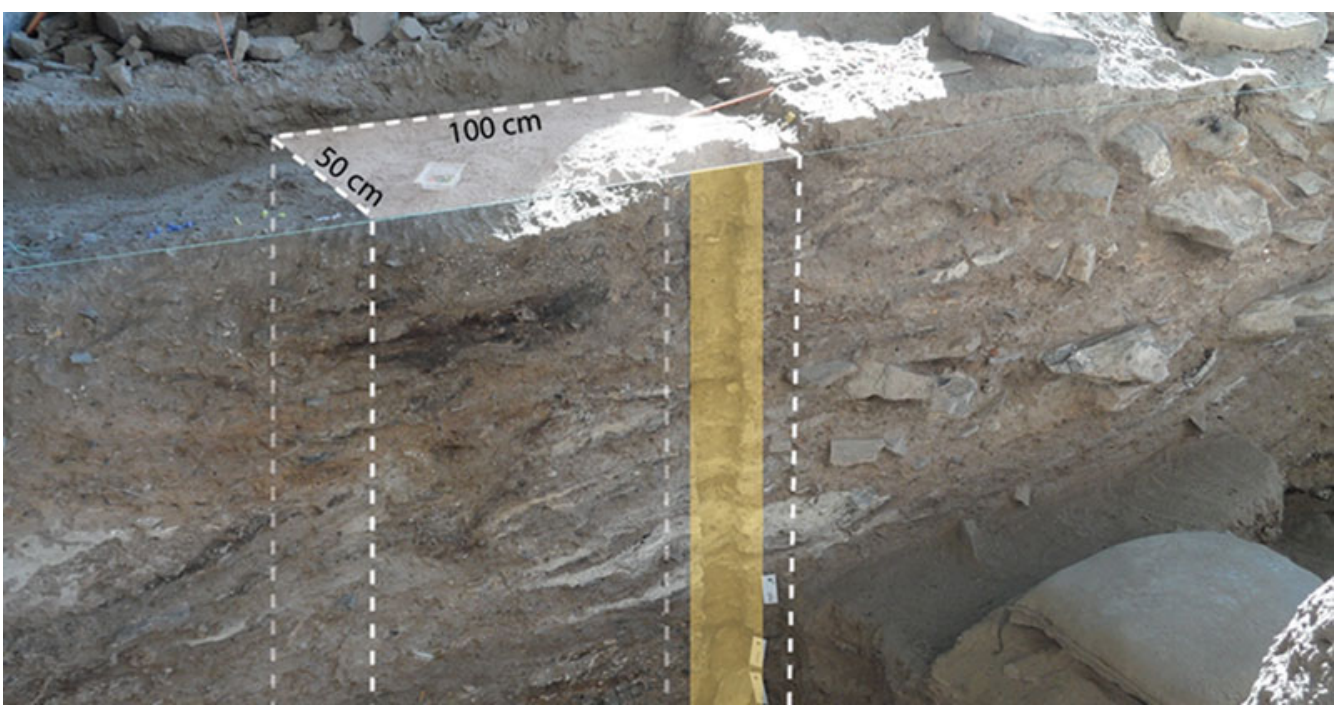

Figure 3. Restored upper part of the Pockenbank Rockshelter profile. Excavated area outlined by dashed lines. Location of column sampled for sedimentological and geochemical analysis highlighted in yellow.

The sequence comprises a succession of seven major units, with clear differences in the colour, texture and composition of the sediments. Intensive anthropogenic activity is documented in the upper part of the sequence (Figure 3), with multi-layered hearths and artefacts, animal bones and ostrich eggshells. Bioturbation (especially insect burrowing) and geogenic post-depositional alterations (precipitation of secondary carbonate and gypsum) of the sediments were observed throughout the sequence, but especially in the lower part.

As the Holocene deposits were removed in 1969, the exposed sequence starts with Early Later Stone Age material of the Late Pleistocene (cf. Ossendorf 2013). The remaining units contain unambiguously Middle Stone Age material. First results from the lower units indicate an age beyond the range of radiocarbon dating.

Pockenbank is one of only a few Middle Stone Age sites in Namibia that is systematically sampled for archaeobotanical remains; charcoal is well preserved, although no pollen has been identified. A sequence of samples for sedimentological, geochemical and 

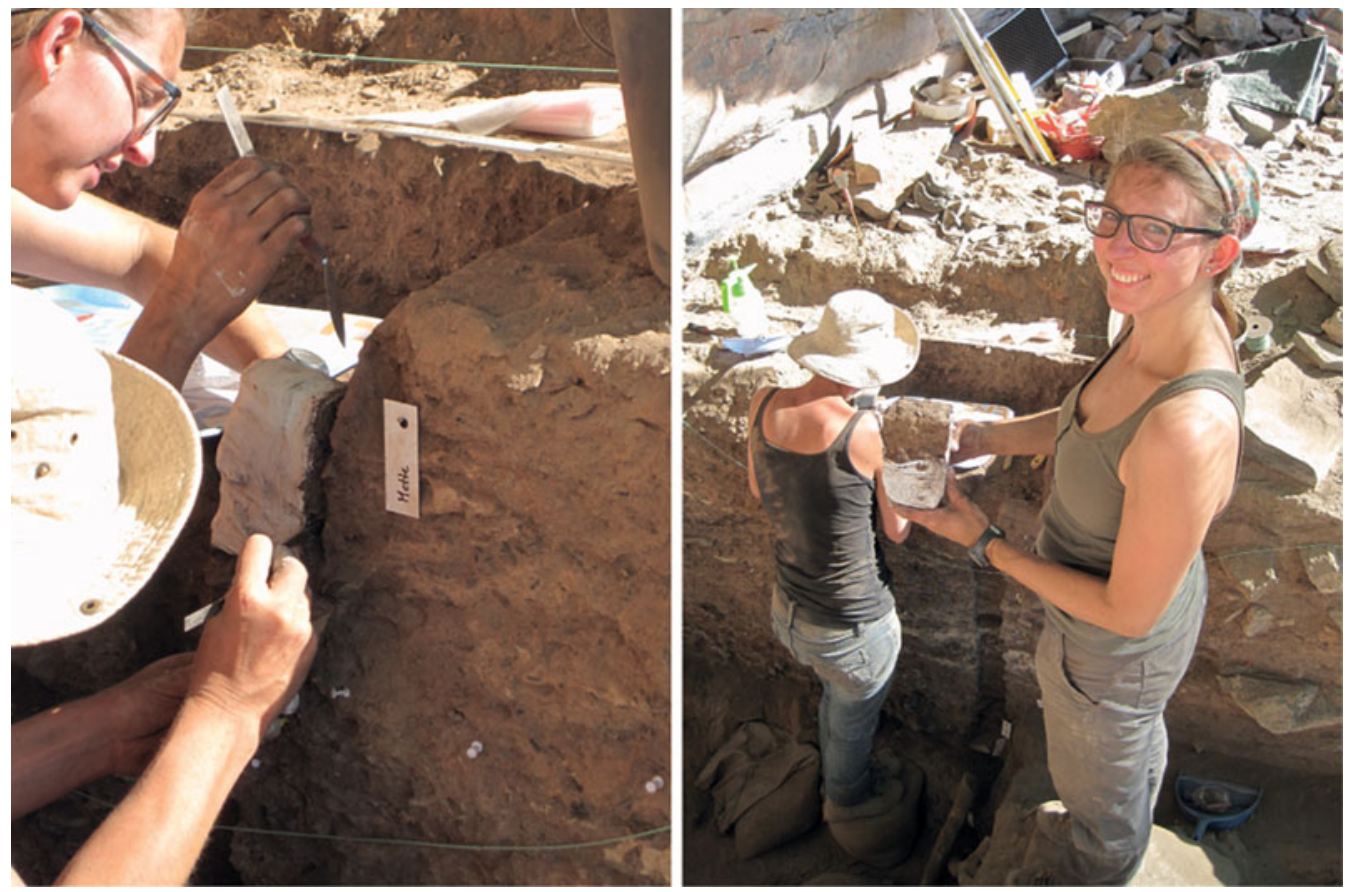

Figure 4. Collecting of samples for micromorphological analysis.

micromorphological analysis has been taken (Figure 4). These samples will shed light on the formation of the archaeological record (Hensel 2016). Samples for isotope analysis and dating (radiocarbon, OSL) have been taken from parts of the profile with fewer signs of bioturbation. The results will be tested against occupation events identified at other sites and will be used to establish a regional age model.

The lithic artefacts recovered during excavation are made of quartzite, quartz and cryptocrystalline silicates (Figure 5). Additionally, artefacts made of organic material have been documented. A few fragments of marine shells were found in the Middle Stone Age unit. Studies on raw material proveniences as well as a technological analysis of the lithic assemblage will shed light on the settlement dynamics of Late Pleistocene foragers. Initial raw material surveys show that the frequently used quartzite varieties were not available locally. It seems plausible that observed changes in raw materials were related to developments in land use as well as the provisioning strategies of hunter-gatherers at the margin of the Namib Desert.

\section{Perspectives}

The archaeological sequence at Pockenbank Rockshelter encompasses critical phases in the evolution of anatomically modern humans in southern Africa. By shifting attention from local centres of innovation to peripheral regions of subcontinental networks, the site has the potential to contribute to a new theoretical perspective on the study of behavioural and technological innovations. Preliminary results indicate that the sequence possesses

(C) Antiquity Publications Ltd, 2016 


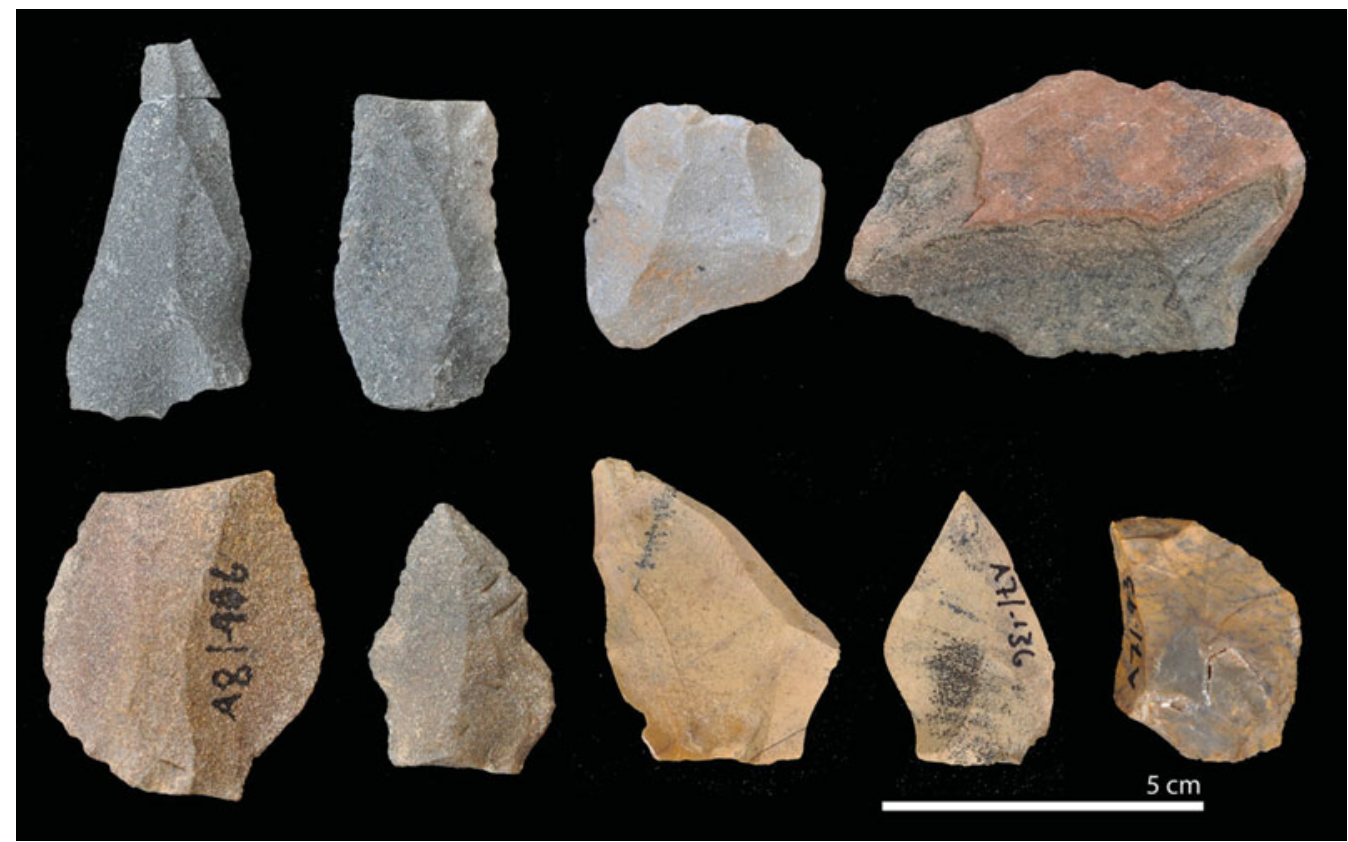

Figure 5. Selection of lithic artefacts made of quartzite and cryptocrystalline silicates: the main raw materials used at Pockenbank.

many of the prerequisites needed to address such research questions successfully. Besides the identification and contextualisation of internal techno-economic changes, the vicinity to the Apollo 11 site also allows for the investigation of inter-assemblage variability on a regional scale. The examination of changing behaviour and adaptation of humans at the junction between different habitats in hyper-arid to semi-arid environments will broaden our view on human lifeways and Middle Stone Age occupation history during the Late Pleistocene in southern Africa.

\section{Acknowledgements}

The project is financed by a postdoctoral research grant from the University of Cologne (2014-2017), awarded to I. Schmidt. We thank the National Museum of Namibia for hosting material and research, the National Heritage Council of Namibia for supporting the project, and the African Research Unit (University of Cologne) for providing research facilities. Thanks to Melli and Mette Gessert, Helmut Paffrath and Helga Goodwin for their great support during fieldwork.

\section{References}

Hensel, E.A. 2016. Geoarchäologische Untersuchungen zur Genese der Sedimentabfolge des Middle und Early Later Stone Age im Pockenbank Rock Shelter Südwest Namibia. Unpublished MA dissertation, University of Cologne.
JACOBS, Z., R.G. ROBERTS, R.F. GALBRAITH,

H.J. Deacon, R. Grün, A. MacKay, P. Mitchell, R. VOGELSANG \& L. WADLEY. 2008. Ages for the Middle Stone Age of southern Africa: implications for human behavior and dispersal. Science 322: $733-35$.

http://dx.doi.org/10.1126/science.1162219 


\section{Isabell Schmidt et al.}

OsSENDORF, G. 2013. Spätpleistozäne Jäger-Sammler des südwestlichen Namibias. PhD dissertation, University of Cologne. Available at: http://kups. ub.uni-koeln.de/6636/ (accessed 16 June 2016).

Vogelsang, R. 1998. Middle-Stone-Age-Fundstellen in Südwest-Namibia. Africa Praehistorica 11. Köln: Heinrich-Barth-Institut.

Vogelsang, R., J. Richter, Z. JACOBS, B. EichHorn, V. LinSEELE \& R.G. RoberTS. 2010. New excavations of Middle Stone Age deposits at Apollo 11 rock shelter, Namibia: stratigraphy, archaeology, chronology and past environments. Journal of African Archaeology 8: 185-218.

http://dx.doi.org/10.3213/1612-1651-10170
WADLEY, L. 2015. Those marvellous millennia: the Middle Stone Age of southern Africa. Azania: Archaeological Research in Africa 50: 155-226. http://dx.doi.org/10.1080/0067270X. 2015.1039236

WENDT, W.E. 1972. Preliminary report on an archaeological research programme in south west Africa. Cimbebasia B(2): 1-61.

(C) Antiquity Publications Ltd, 2016 